ination is usually distributed in the body's extracellular fluid, and a large proportion appears in the thyroid gland. This selective deposition provides a convenient means of assessing the extent of individual contamination. Buchan and Brindle estimated by scintillation counting the amount of iodine-131 in the thyroid glands of each of 39 persons whose households contained a patient recently treated for hyperthyroidism with this isotope. In most of the families the recommended precautions were observed, but in a few, selected for intelligent understanding of the purpose of the survey, the precautions were ignored. In almost all of the 39 persons iodine-131 was readily detected in the thyroid. The doses of radiation they received from it were small, though they were larger than the dose incurred by the thyroid or other organs from a year's radioactive fall-out at present levels. In some instances they were comparable to a year's natural background radiation. Further experiments are in progress to estimate the additional dose due to external gamma-radiations from the patients.

Buchan and Brindle suggest that, except where very young children are concerned, precautions to minimize contamination from iodine-131 in the home should be abandoned and that no restriction is needed on the amount of this isotope that may be given to outpatients-even at the level of 200 millicuries or more used in the treatment of thyroid carcinoma. These proposals may not be readily accepted, but the Plymouth study does show that the contamination hazard is adequately contained by the present regulations.

\section{Colombo Medical School Centenary}

The centenary of the medical school at Colombo, in Ceylon, is an event well worthy of note. The school has sustained and is sustaining a role of outstanding importance in medical research and education in South-East Asia. This has been recognized by the World Health Organization, which last month supported a seminar in Colombo to do honour to the staff and accomplishments of the school; among the secondary objectives of this were to bring together recent work of importance to Ceylon (and particularly that done in Ceylon) and to review the ways in which medicine might be expected to progress in the next few years of the school.

The history of the school from 1870 is one of continual enlargement and achievement. It was recognized by the General Medical Council of Great Britain as long ago as 1887 -as the result of a Privy Council held on 29 December at Osborne House in the Isle of Wight. Women students were admitted five years later, in 1892. It was in Colombo, between 1912 and 1914, that Sir Aldo Castellani-now aged 93discovered Toxoplasma, and where in the early 1930s E. Brumft discovered Plasmodium gallinaceum, the malaria parasite of fowls. The finding of the pre-erythrocytic form of this organism in the liver paved the way to the recent work by Short and Garnham on the human pre-erythrocytic form of malaria. It was therefore particularly appropriate that Professor P. C. C. Garnham should attend the centenary celebrations.

Among notable work latterly done by Ceylonese has been the uncovering of monkey malaria by Professor A. S. Dissanaike. Five species have been found and considerable importance is attached to the transmission to man of these forms of malaria. Another notable achievement has been the virtual eradication of the malayi form of filariasis (Brugia malayi) from the island and the control of the common filarial infection, Wucheria bancrofti. Malaria eradication appeared to be coming to a highly successful conclusion in Ceylon until 1967, when a major outbreak occurred, affecting at least two million of its 14 million inhabitants. Nevertheless, the factors underlying this outbreak are themselves the subject of important investigations that are applicable to other endemic areas. Perhaps the most important conclusion to date is that eradication is virtually impossible, and continuous vigilance involving much expense and staff is needed in areas like Ceylon once the transmission of malaria has been reduced to a low level.

Medical educators in Ceylon have been experimenting with changes in the curriculum, and reducing substantially the load of formal work. The need to encourage training in decision taking at the expense of factual instruction was particularly emphasized in the seminar.

The Ceylonese medical profession are to be congratulated on their important achievements in the past 100 years, and we wish them well in the second century of the Colombo Medical School.

\section{Role of the Nurse}

Earlier this year, while Secretary of State in the Department of Health and Social Security, Mr. Crossman circulated a letter to boards of governors, hospital management committees, and others on actions to be taken to improve the nursing situation. He also set up a committee, which has now started work, with Professor Asa Briggs in the chair and these terms of reference:

"To review the role of the nurse and the midwife in the hospital and the community and the education and training required for that role, so that the best use is made of available manpower to meet present needs and the needs of an integrated health service."

Both actions were prompted by disturbing facts. The number of student nurses is falling. In September 1967 there were 56,141 in training; in March 1969 there were 49,822. Many of the teaching hospitals are for the first time in their history embarrassed by lack of recruits. The growth in the number of trained staff has almost ceased at a time when the demand for their services in specialized units is rising.

A hundred years ago women were pressing for education and employment, and the great nursing pioneers opened up the field of hospital work at a time when medicine and surgery were making gigantic strides. It was convenient to have an assistant to undertake routine observations, so thankfully laying down the scrubbing brush the nurse took up the thermometer and began her progress towards professionalism as the servant of the doctor. The profession as constituted was predestined to exploitation-female, dedicated, living in "homes" that resembled convents. Doctors viewed their progress dubiously. Up to twenty years ago it was common to hear fears that nurses were becoming "little doctors," but today the need for an educated colleague is apparent.

Nurses are a heterogeneous group. There are students engaged on university courses leading to degrees as well as registration; students and registered nurses who may have G.C.E. A-level subjects, or no educational qualification at all; enrolled nurses dissatisfied with their status; auxiliaries who (if fortunate) have an in-service training. A large number are foreign-born and some have difficulty in speaking English. Is the nation aware of the burden it is imposing on these women? We should be alert to what we are doing to shore up the hospital system. 
Perhaps now is the time to ask, Must all nurses be trained in hospital? There is a big field of work in the community for which long experience in major surgery or with positivepressure respirators is unnecessary. Of all the students who arrive at the hospital school expressing a desire to help people more than a third will find the physical and emotional demands of hospital life too severe and will give up. Many of these regret their inability to continue and might have much to offer in community service.

Most university students build their degree by success in course units of their choice, and the Briggs Committee might find a parallel here for attaining registration by gaining qualification in a series of different nursing courses. The student who was drawn to hospital work could spend the greater part of her training there, while the community nurse would select only the basic hospital course. The student who left before registration might later gain further qualifying units as domestic circumstances allowed. It is to be hoped that the committee will not confine itself to studying the present, or it will be overtaken by the future.

\section{Osteoporosis and Fluoride Therapy}

One striking feature of osteoporotic bone is that it can still produce callus after a fracture. If trauma can induce new bone formation then it should be possible to reproduce the effect metabolically. Fluoride, one of the possible stimuli, has different effects on bone according to the age of the subject, the rate of administration, and the length of time for which it is given. It is incorporated into mineral by a process of hydroxyl radical substitution, so that the mineral becomes more resistant to resorptive processes. ${ }^{12}$ In young bone this chemical substitution may make the mineral more resistant to the enhancement of resorption by parathyroid hormone. ${ }^{3}$ Fluoride may also be incorporated in bone as fluorocitrate, ${ }^{4}$ which is highly toxic to mitrochondrial respiration. Changes in citrate production in bone induced by feeding large amounts of fluoride in a short time led to the deposition of $0.4 \%$ fluoride in bone and a $40 \%$ reduction in the amount of bone citrate, ${ }^{5}$ though the vitamin $\mathrm{D}$ enhancement of the bone citrate production was not inhibited. 6 Fluoride may also interfere with enzyme action by forming metalion complexes and in this way affect enzymes such as D.N.A. polymerase, ${ }^{7}$ though this occurs only at much higher concentrations than is found overall in fluorotic bone. When large doses have been given to animals they showed osteomalacia and compensatory hyperparathyroidism, reflected in striking changes in the parathyroid glands. ${ }^{8}$ These effects explain how the exchangeable pool and the rates of bone formation and resorption are raised in skeletal fluorosis ${ }^{9}$ - effects not found when administration was limited to three weeks. ${ }^{10}$ In this context calcium intake is of great importance; since if it is kept high and possibly enhanced by administration of vitamin $\mathrm{D}$ the balance is tipped in the direction of bone formation, and animal studies show an increase in bone ash. ${ }^{11} 12$ Indeed, if the calcium intake is increased in growing animals the osteomalacic aspects of acute fluoride administration can be completely prevented. ${ }^{13}$ These findings may explain conflicting reports of the effects of fluoride intake on the prevalence of osteoporosis in areas of varying fluoride content in the water. In Texas ${ }^{14}$ and North Dakota $^{15}$ there was less osteoporotic bone disease in high fluoridinated areas while in New York ${ }^{16}$ and Sweden ${ }^{17}$ no such relationship was noted.

So, because of the encouraging skeletal sclerosis produced in patients with myelomatosis treated with fluoride and calcium supplements ${ }^{18}$ attention has been focused on inducing similar changes in osteoporosis. Histological and microradiographic studies have shown increased thickness in bony trabeculae ${ }^{19}$ in both ribs and iliac crests. On the basis of these changes several groups reporting at a meeting in Switzerland last year $^{20}$ concluded that new bone formation could be frequently found in osteoporotic patients treated by fluoride and that it must now be accepted as a therapeutic procedure. The quality of the "new bone" formed under such conditions is, however, still in doubt, especially if adjuvant calcium, vitamin $\mathrm{D}$, or androgen therapy is not given as well. ${ }^{21}$ Experiments on animals have shown that simple administration of fluoride makes the bone more flexible but that its load bearing qualities are impaired ${ }^{22}$ and its breaking stress is significantly reduced. ${ }^{8}$

How, then, having induced the formation of, albeit rather poor quality, new bone by the use of fluoride, can the gain in matrix and cellularity be consolidated? One area of intense study is the relationship between the bone marrow and the bone-forming elements, since there is evidence of fatty infiltration of the marrow in osteoporosis. ${ }^{23}$ Once again the osteoporosis of myeloma may provide some indication that a combination of androgens and fluoride may induce hypertrophy of the marrow on the one hand and new bone formation on the other. ${ }^{24}$ Against the possible advantages of long-term fluoride therapy on the bone must be set its effects on other organs, such as gut irritation, adrenal hypertrophy, possible effects on the optic fundus, and the depression of colagen synthesis. ${ }^{25}$ The appeal of using a potentially toxic substance in the treatment of a disease of unknown aetiology must be tempered by rigorous long-term assessment of its effects on bone and other organs.

1 Posner, A. S., Eanes, E. D., Harper, R. A., and Zipkin, I., Archives of Oral Biology, 1963, 8, 549 .

2 Young, R. A., Van Der Lugt, W., and Elliott, J. C., Nature, 1969, 223, 729.

- Goldhaber, P., Israel fournal of Medical Sciences, 1967, 3, 617.

4 Peters, R. A., Shorthouse, M., and Ward, P. F. V., Proceedings of the Nutrition Society, 1969, 28, 46A.

- Hac, L. R., and Freeman, S., American Fournal of Physiology, 1967, 212, 213.

- Hac, L. R., and Freeman, S., American fournal of Physiology, 1969, 216,

'Hellung-Larsen, P., and Klenow, H., Biochimica et Biophysica Acta, 1969, 190, 434.

Faccini, J. M., Calcified Tissue Research, 1969, 3, 1.

- Rao, B. S. N., Siddiqui, A. H., and Srikantia, S. G., Metabolism, 1968, 17,366 .

10 Lukert, B. P., Bolinger, R. E., and Meek, J. C., Fournal of Clinical Endocrinology and Metabolism, 1967, 27, 828.

11 Hauck, H. M., Steenbock, H., and Parsons, H. T., American fournal of Physiology, 1933, 103, 480.

12 Lawrenz, M., and Mitchell, H. H., Fournal of Nutrition, 1941, 22, 91.

13 Burkhart, J. M., and Jowsey, J., Fournal of Laboratory and Clinical Medicine, 1968, 72, 943.

14 Leone, N. C., Stevenson, C. A., Hilbish, T. F., and Sosman, M. C., American fournal of Roentgenology, Radium Therapy and Nuclear Medicine, 1955, 74, 874.

16 Bernstein, D. S., Sadowsky, N., Hegsted, D. M., Guri, C. D., and Stare, F. J., Fournal of the American Medical Association, 1966, 198, 499. 16 Korns, R. F., Public Health Reports, 1969, 84, 815.

17 Alfram, P. A., Herbborg, J., and Nilsson, B. E. R., Acta Orthopaedica Scandinavica, 1969, 40, 137.

18 Cohen, P., Nichols, G. L., jun., and Banks, H. H., Clinical Orthopaedics and Related Research, 1969, 64, 221.

10 Jowsey, J., and Kelley, P. J., Proceedings of the Mayo Clinic, 1968, 43, 435.

20 Kuhlencordt, F., Kruse, H. P., Lozano-Tonkin, C., and Eckermeier, L., In Fluoride in Medicine, ed. Thomas L. Vischer, p. 169. Benn, Huber, 1970.

21 Adams, P. H., and Jowsey, J., Annals of Internal Medicine, 1965, 63, 1151.

2 Beary, D. F., Anatomical Record, 1969, 164, 305.

23 Meunier, P., Aaron, J., Edouard, C., and Vignon, G., Presse Médicael, 1970, 78, 531.

24 Cohen, P., and Gardner, F. H., New England Fournal of Medicine, 1964, 271, 1129.

25 Hodge, H. C., and Smith, F. A., Annual Review of Pharmacology, 1968, 8, 395 . 